\title{
Performance Analysis of QoS Parameters of MANET on Mobility and Energy based Model with Different MANET Routing Protocols
}

\author{
I. Vijaya ${ }^{1 *}$, Amiya Kumar Rath ${ }^{2}$, Bhagabat Puthal ${ }^{3}$, Debahuti Mishra ${ }^{4}$ and S. Satapathy ${ }^{5}$ \\ 'Department of Computer Science and Engineering, Siksha 'O' Anusandhan University, Bhubaneswar - 751030, \\ Odisha, India; ivijaya@rediffmail.com \\ ${ }^{2}$ Department of Computer Science and Engineering and IT, V.S.S.U.T, Burla - 768018, Odisha, India; \\ amiyaamiya@rediffmail.com \\ ${ }^{3}$ Department of Computer Science and Engineering Retired Professor, IGIT, Sarang - 759146, Odisha, India; \\ bhagabat.puthal@gmail.com \\ ${ }^{4}$ Department of Computer Science and Engineering, Siksha 'O' Anusandhan University, Bhubaneswar - 751030, \\ Odisha, India; mishradebahuti@gmail.com \\ ${ }^{5}$ Department of Computer Science and Engineering, Siksha 'O' Anusandhan University, Bhubaneswar - 751030, \\ Odisha, India; sandeepkumar04@gmail.com
}

\begin{abstract}
Objectives: A network is group of devices that are connected to each other called as nodes. The nodes can be mobile or static. The performance of mobile Adhoc wireless networks (MANETs) helps to identify the type of applications that are supported by the network. Our objective is Performance analysis of QoS parameters of MANETs on Mobility \& Energy based Model with Routing Protocols. Method/Analysis: The various network scenarios of MANETS are simulated using NS2.35. Protocols used to analyze performance are AODV, DSDV and DSR. Network layer parameters (throughput, packet delivery ratio, normalized routing overhead and average end-to-end delay) are evaluated. Network scenarios are generated through variation in pause time and number of nodes. Area of simulation is formed in $600 * 600 \mathrm{~m} * \mathrm{~m}$ area. Findings/ Results: The mobiles devices in the network get connected only when there is a demand for it. The reactive gateway discovery algorithm is used in AODV and DSR. With the random movement of nodes in the simulated area (direction) and variation in mobility, the delay and packet drop increases but PDR and throughput decreases. There is a significant differential observed while measuring the performance. Our observation with respect to DSR was it reacted well for two parameters delivery ratio and routing overhead. Average delay was less in AODV and DSDV performed well providing loop free path. Conclusion: After the simulation study and all experimental evaluations we can conclude that the DSR protocol dominates all other protocols like AODV and DSDV. The Dynamic Source Routing protocol in mobility and energy based model for throughput, packet delivery ratio performs well than AODV and DSDV. The adverse result is with the increase of node speed, routing overhead increased for DSR. Positive aspect of DSR was that average energy consumption was quite low in contrast to AODV and DSDV.
\end{abstract}

Keywords: Average Energy Consumption, Average End-To-End Delay, MANET, Normalized Routing Overhead, Packet Delivery Ratio, Throughput

\section{Introduction}

Mobile Ad-hoc Network (MANETs) in recent years has gained attention of researchers. Research has been pro- gressed in diverse aspects of MANET $\stackrel{1-9}{\text {. The motivation }}$ behind the various diversities is due to its characteristics such as; dynamic topology, bandwidth constrained and

${ }^{*}$ Author for correspondence 
energy constrained operations ${ }^{10,11}$. There is no fixed base station, the topology is very dynamic i.e.; sometimes the node becomes as host or a router or a gateway or a simple node with no neighbors. There are some applications like battlefields or military applications where this kind of infrastructure less can be seen. The communication between the nodes takes place when they are within the transmission range, and when they are out of the range the communication is done through the intermediate node through multiple hops ${ }^{7.9}$. There are three basic characteristics of MANET such as; (a) the network change is unpredictable and the nodes moves move freely in arbitrary directions resulting in dynamic topology; (b) the throughput is less due to interferences such as noise, fading effects and the bandwidth available is very less known as constrained bandwidth and (c) the portal devices need electrical devices like battery chargers etc. resulting in energy constrained ${ }^{6,9}$.

There are many related researches done on the Adhoc network models and have been successful in various fields of network. The challenges faced by the researchers are the data that is used to verify the results, mostly the data is synthetic data and the data used is very uncertain, vague and approximate. This study of work done in mobile adhoc network is summarized here. Author ${ }^{11}$ simulated evaluated three protocols (OLSR, AODV \& DSDV) for the network scenarios in different time intervals. The simulation by the author was carried out by varying number of nodes.Author ${ }^{12}$ analyzed and evaluated performance for different metrics values with predefined constraints. The simulation was performed by varying mobility on different scenario with fixed number of nodes. Author ${ }^{13}$ described the behavior of routing protocols on mobility \&traffic. The performance for parameters delay and loads in MANET has been analyzed by Author ${ }^{14}$. Author ${ }^{15}$ performed studies on the effect of mobility on performance of on-demand routing protocols. Author $\frac{16}{16}$ evaluated protocols using different packet size. Author ${ }^{17}$ discussed various routing protocol and several routing schemes proposed for MANET. The routing strategy was used to classify the routing schemes. Author ${ }^{18}$ described various broadcast schemes and recommended to map probability-based and Omni-directional broadcast. Author ${ }^{19}$ demonstrated performance of a policy-based MANETs. They presented techniques to develop DRAMA (Dynamic Re- Addressing and management system) architecture. Author ${ }^{20}$ proposed multicasting algorithm for mobile adhoc network (MANET) - ANMAS (Adhoc network multicasting with Ant system). In this method, ants 'pheromone' was used for the indirect communication to obtain dynamic topology change information and achieve a 'tolerable' multicasting group. Author ${ }^{21}$ measured the inefficiency of the overlay multicasting. Author ${ }^{22}$ proposed and presented results of a shared tree variant of Shared-Tree Multicast Zone Routing Protocol.

Each type of application that a MANET supports can be identified by evaluating the performance of mobile adhoc wireless networks ${ }^{23,24}$. The network performance metrics used, analyzed and evaluated for our study are network layer parameters as listed $\frac{25}{5}$

a) $\mathrm{TP}=$ throughput

b) $\mathrm{PDR}=$ packet delivery ratio

c) $\mathrm{AD}=$ average end-to-end delay and

d) $\mathrm{NRO}=$ normalized routing overhead .

In our work, we considered a proactive and two on-demand reactive routing protocols i.e.; DSDV and (AODV, DSR). The mobiles devices in the network get connected only when there is a demand for it. The algorithm used in ADODV and DSR is gateway discovery.

\section{MANET Routing Protocols}

In adhoc networks routing is a complex problem due to its dynamic nature. The process of designing communications and the right protocol for the type of network is quite a challenging process. Considering the most important aspect of communication is to establish a route, maintain and transfer data between nodes or devices, protocols play an important role ${ }^{11}$. Numerous studies and researches have been done in the area of designing a protocol ${ }^{1-3}$. Depending on the type of complex network under study, researchers have suggested multitude of protocols ${ }^{12}$. To evaluate the efficiency of a protocol, mobility and traffic are two the important aspects that should be considered. These protocols support a broader range of MANET applications. The best-effort basis is chosen to establish and maintain routes between nodes ${ }^{13}$.

\section{Strategies of Routing Protocols}

The network structures supporting any routing protocol are classified into flat, hierarchical and geographical 
position assisted. There are three very common and predominantly used routing strategies; proactive strategy, reactive strategy and hybrid strategy ${ }^{24-29}$. Proactive strategies are table-driven and reactive strategies are demand-driven. Hybrid is a combination of proactive and reactive strategies. Classification of adhoc protocols at a broader level is shown in Figure 1. The explanations along with their characteristics of these protocols are briefly explained in the following sub-sections.

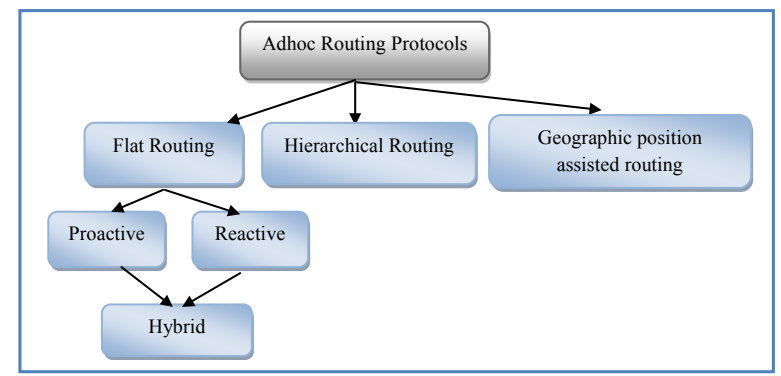

Figure 1. Categorization of adhoc routing protocols.

\subsection{Proactive Strategy}

In Proactive strategy, each node in the network maintains the routing information. Maintaining the route of the node helps to forward the packet to the desired node making search faster. Examples of these protocols are Optimized Link State Routing (OLSR), Destination Sequenced Distance Vector (DSDV), Fisheye State Routing (FSR), and Fuzzy Sighted Link State (FSLS). The limitation of this category of protocols is that they utilize high network resources due to continuous updation of routing table information. Table $\mathbf{1}$ describes the characteristics of the proactive type of protocols $\frac{27,28}{}$.

\subsection{Reactive Strategy}

The basic principle of this scheme is that each node in the network maintains active route destinations only. This scheme overcomes high resource utilization as data sending and receiving is not continuous. Communication

Table 1. Characteristics of Proactive protocols

\begin{tabular}{|c|c|}
\hline Protocol & Characteristics \\
\hline $\begin{array}{l}\text { DSDV } \\
\text { (Destination } \\
\text { Sequenced Distance } \\
\text { Vector) }\end{array}$ & $\begin{array}{l}\text { - A routing node is maintained for each node with the destination information, next hop and } \\
\text { required no. of hops to reach the required destination } \\
\text { - Periodically route information is updated based on the route information broadcasted. } \\
\text { - Two packets are carried to the nodes, one containing routing information (full dump) and second } \\
\text { carry only the delta changes from the full dump (incremental). } \\
\text { - Sequence numbers are maintained for the routes and updates to the routes are based on the } \\
\text { sequence number. } \\
\text { - Routing table is updated ignoring the old sequence number with the recent sequence number } \\
\text { - Already existing sequence number if matches, then information of next hop and \# of hops are } \\
\text { considered for update (best metrics). } \\
\text { - The new information is then broadcasted into the packet. }\end{array}$ \\
\hline $\begin{array}{l}\text { WRP } \\
\text { (Wireless } \\
\text { Routing Protocol) }\end{array}$ & $\begin{array}{l}\text { - It is modified version of DSDV. } \\
\text { - A set of four tables - distance, routing, link cost and message retransmission are maintained. }\end{array}$ \\
\hline $\begin{array}{l}\text { OLSR } \\
\text { (Optimized Link } \\
\text { State Routing } \\
\text { Protocol) }\end{array}$ & $\begin{array}{l}\text { - Each node uses its most recent information to route a packet. } \\
\text { - Multipoint Relay nodes are selected based on the greedy algorithm. } \\
\text { - OLSR protocol performs hop by hop routing. } \\
\text { - The source node communicates with its two-hop neighbors through multi point relay nodes. }\end{array}$ \\
\hline $\begin{array}{l}\text { FSR } \\
\text { (Fisheye State } \\
\text { Routing) }\end{array}$ & $\begin{array}{l}\text { - The network structure is like 'fisheye. } \\
\text { - Each node has only routing information of the nearest node. } \\
\text { - The information contained is exact and accurate. }\end{array}$ \\
\hline
\end{tabular}


overhead is also reduced and is mostly used. Table 2 describes the characteristics of the reactive type of protocols ${ }^{27-30}$.

Table 2. Characteristics of Reactive protocols

\begin{tabular}{|c|c|}
\hline Protocol & Characteristics \\
\hline $\begin{array}{l}\text { AODV } \\
\text { (Adhoc } \\
\text { On-demand } \\
\text { Distance } \\
\text { Vector) }\end{array}$ & $\begin{array}{l}\text { - Each node establishes routes only } \\
\text { when requested by the source node } \\
\text { and caches it. } \\
\text { - Nodes maintain a tree like structure } \\
\text { containing the local connectivity of } \\
\text { information and when the cache is } \\
\text { unable to serve the requested data, } \\
\text { source flags a RREQ route request } \\
\text { broadcast packet. } \\
\text { The receiving node checks the } \\
\text { availability of the information of the } \\
\text { destination node in its cache and } \\
\text { sends a (RREP) route reply. } \\
\text { - Nodes keep track of the RREQ's } \\
\text { source IP address and broadcast ID. } \\
\text { - The nodes that are part of an } \\
\text { active route contain connectiv- } \\
\text { ity information by broadcasting } \\
\text { local 'Hello' messages to its } \\
\text { neighbors. } \\
\text { The source node reinitiates route } \\
\text { discovery as soon as it receives route } \\
\text { error (RERR) indicating link break } \\
\text { to the destination. }\end{array}$ \\
\hline $\begin{array}{l}\text { DSR } \\
\text { (Dynamic } \\
\text { Source } \\
\text { Routing) }\end{array}$ & $\begin{array}{l}\text { - The sender node correlates the } \\
\text { chain of nodes to reach the destina- } \\
\text { tion for transmitting the packets. } \\
\text { - For transmission of packets, the } \\
\text { source node searches route cache } \\
\text { for destination. } \\
\text { - Each packet contains sequence of } \\
\text { hops taken by the route request } \\
\text { packet during route discovery. }\end{array}$ \\
\hline $\begin{array}{l}\text { HSR } \\
\text { (Hierarchical } \\
\text { State } \\
\text { Routing) }\end{array}$ & $\begin{array}{l}\text { - The nodes are partitioned into clus- } \\
\text { ters and each cluster has a cluster } \\
\text { head that is responsible for passing } \\
\text { its information to neighbor nodes. } \\
\text { - The structure used is hierarchical } \\
\text { structure which combines cluster- } \\
\text { ing technique with the location } \\
\text { management. } \\
\text { - The cluster head is used as gateway } \\
\text { to deliver the data to any part of the } \\
\text { other network. }\end{array}$ \\
\hline
\end{tabular}

\begin{tabular}{|c|c|}
\hline $\begin{array}{l}\text { TORA } \\
\text { (Temporally } \\
\text { Ordered } \\
\text { Routing } \\
\text { Algorithm) }\end{array}$ & $\begin{array}{l}\text { - The source node determines the } \\
\text { direction of the link between two } \\
\text { nodes and uses a parameter 'height' } \\
\text { to establish a link for the shortest } \\
\text { path. } \\
\text { - The source initiates a route to des- } \\
\text { tination by broadcast and the node } \\
\text { that has the destination replies with } \\
\text { an update of the parameter height. } \\
\text { - The links from source to destination } \\
\text { are directed links in descending } \\
\text { order of height. } \\
\text { - The invalid links are removed from } \\
\text { the network when the node cannot } \\
\text { find the neighboring links. }\end{array}$ \\
\hline $\begin{array}{l}\text { LMR } \\
\text { (Light } \\
\text { Weight } \\
\text { Mobile } \\
\text { Routing) }\end{array}$ & $\begin{array}{l}\text { - It combines two processes of route } \\
\text { establishment and route mainte- } \\
\text { nance. } \\
\text { - It used the link reversal algorithm. } \\
\text { - The source establishes a route by } \\
\text { query packets and failures are } \\
\text { recorded to maintain the route }\end{array}$ \\
\hline
\end{tabular}

\subsection{Hybrid Strategy}

The basic principle of this scheme is that both the proactive and reactive strategies are clubbed on the network. The network is further divided into clusters (intra \& inter clusters). In the intra-clusters the proactive protocol is used and reactive protocol is used in inter-cluster. Table 3 describes the characteristics of the hybrid type of protocols $\frac{31,32}{}$.

Table 3. Characteristics of hybrid protocols

\begin{tabular}{|l|l|}
\hline Protocol & Characteristics \\
\hline ZRP & $\begin{array}{l}\text { The nodes are divided into zones and each zone } \\
\text { Routing } \\
\text { Protocol) }\end{array}$ \\
& $\begin{array}{l}\text { has a set of interior nodes (each node having } \\
\text { The routing in intra-zone is done by proactive } \\
\text { approach. } \\
\text { The neighbor discovery is done by neighbor } \\
\text { discovery protocol. } \\
\text { The outside zone route discovery is done by } \\
\text { reactive approach } \\
\text { The source nodes initiate the route discovery, } \\
\text { through a sequence of checks i.e.; check in intra- } \\
\text { zone, then check in the peripheral node and } \\
\text { finally check outside the zone. In this way route } \\
\text { discovery is been done. }\end{array}$ \\
\hline
\end{tabular}




\begin{tabular}{|l|l|}
\hline SHARP & The nodes are grouped into zones and nodes \\
(Sharp & within the proactive zone maintain information \\
Hybrid & with respect to the central node. \\
Adaptive & The zone radius determines the nodes belonging \\
Routing & to a particular zone. \\
Protocol) & $\begin{array}{l}\text { In this scheme, if a node is unable to retrieve } \\
\text { information of destination node it uses reactive } \\
\text { mechanism of (REQ-REP) to establish the route } \\
\text { The proactive zones are the collectors of packets. }\end{array}$ \\
\hline
\end{tabular}

The parametric comparison ${ }^{27}$ of above mentioned three routing protocols along with their relative advantages and disadvantages ${ }^{28}$ are shown in Table 4 and Table 5 respectively.

Table 4. Parametric comparison of routing protocols

\begin{tabular}{|c|c|c|c|}
\hline Parameters & Proactive & Reactive & Hybrid \\
\hline $\begin{array}{l}\text { Availability } \\
\text { of routing } \\
\text { information }\end{array}$ & $\begin{array}{l}\text { Continuously } \\
\text { available }\end{array}$ & $\begin{array}{l}\text { Only when } \\
\text { required }\end{array}$ & $\begin{array}{l}\text { Proactive and } \\
\text { Reactive }\end{array}$ \\
\hline Latency & $\begin{array}{l}\text { Comparatively } \\
\text { Low }\end{array}$ & $\begin{array}{l}\text { Ideally } \\
\text { High }\end{array}$ & $\begin{array}{l}\text { Zone specific } \\
\text { - High outside } \\
\text { and Low inside }\end{array}$ \\
\hline $\begin{array}{l}\text { Mobility } \\
\text { support }\end{array}$ & $\begin{array}{l}\text { Frequently gets } \\
\text { updated }\end{array}$ & $\begin{array}{l}\text { Mainte- } \\
\text { nance of } \\
\text { route }\end{array}$ & $\begin{array}{l}\text { Proactive \& } \\
\text { Reactive }\end{array}$ \\
\hline $\begin{array}{l}\text { Periodic } \\
\text { updates }\end{array}$ & $\begin{array}{l}\text { Needed } \\
\text { (during a } \\
\text { change in } \\
\text { topology of the } \\
\text { network) }\end{array}$ & Not needed & $\begin{array}{l}\text { Needed inside } \\
\text { the cluster } \\
\text { zone }\end{array}$ \\
\hline $\begin{array}{l}\text { Routing } \\
\text { network } \\
\text { structure }\end{array}$ & $\begin{array}{l}\text { Flat/ } \\
\text { Hierarchical }\end{array}$ & Flat & Hierarchical \\
\hline $\begin{array}{l}\text { Routing } \\
\text { overhead }\end{array}$ & $\begin{array}{l}\text { Comparatively } \\
\text { High }\end{array}$ & Ideally Low & $\begin{array}{l}\text { Normal to } \\
\text { Medium } \\
\end{array}$ \\
\hline $\begin{array}{l}\text { Routing } \\
\text { scheme }\end{array}$ & Table driven & $\begin{array}{l}\text { On } \\
\text { demand }\end{array}$ & $\begin{array}{l}\text { Combination } \\
\text { of both }\end{array}$ \\
\hline Scalability & Low & $\begin{array}{l}\text { Designed } \\
\text { for small } \\
\text { networks }\end{array}$ & $\begin{array}{l}\text { Designed for } \\
\text { large networks }\end{array}$ \\
\hline $\begin{array}{l}\text { Storage } \\
\text { capacity }\end{array}$ & High & Low & $\begin{array}{l}\text { Depends on } \\
\text { the size of } \\
\text { zone. }\end{array}$ \\
\hline
\end{tabular}

Table 5. Advantages and disadvantages of routing protocols

\begin{tabular}{|l|l|l|}
\hline Protocol & Advantages & Disadvantages \\
\hline Proactive & $\begin{array}{l}\text { Low latency as } \\
\text { information is } \\
\text { always available }\end{array}$ & $\begin{array}{l}\text { High Overhead as } \\
\text { information is flooded } \\
\text { in the whole network }\end{array}$ \\
\hline
\end{tabular}

\begin{tabular}{|l|l|l|}
\hline Reactive & $\begin{array}{l}\text { Low overhead, path } \\
\text { availability when } \\
\text { needed. }\end{array}$ & High Latency \\
\hline Hybrid & $\begin{array}{l}\text { Suitable for large } \\
\text { networks and } \\
\text { information is up } \\
\text { to date }\end{array}$ & Increases Complexity \\
\hline
\end{tabular}

\section{MANET Mobility Model}

Mobility is defined as the movement of mobile users in a network. Theoretically mobility model can be used to represent these mobile users. The mobility model uses protocols to set up routes between nodes and also help in discovering of routes ${ }^{33}$. To represent a model of the mobile devices in the network, analytical or simulation models are used. The relationship between the mobility model and the protocol performance is represented by the Figure 2. The mobility models play an imperative part in assessing the ad hoc protocol performance. It describes multitude of operations like movement pattern and presence of mobile nodes in the location, the speed of a node and the acceleration of nodes with the change of the parameter time ${ }^{29}$. The type of model used influences two aspects i.e.; performance and derivation of solution to use the best model for complex situation. The most widely and predominantly used mobility model in MANET simulations is the random waypoint model that is described in following section $\stackrel{34}{ }$.

Mobility Model $\rightarrow$ Average Connected Path $\rightarrow \quad$ Routing Algorithm

Figure 2. Relationship of Mobility Model and Adhoc routing Protocols

\subsection{Random Waypoint Model}

Random way point is the simplest and widest used model in most of the simulations was first proposed by Johnson and Maltz ${ }^{35}$ which became a benchmark mobility model to evaluate the MANET routing protocols. It was available with the widely used network simulator NS2. The basic principle of operation of this model is the nodes move independently to a randomly chosen location (also termed as destination) with a constant velocity chosen uniformly. The velocity and direction are independent of each other. A pause time is included between the change in destination and velocity of a node. At the destination, the node stops for the pause period defined. After the expiry of the pause time, another random node is cho- 
sen as destination within the simulation area. The speed is also chosen randomly during the new cycle of simulation ${ }^{35}$. This process is repeated until end of the cycle. Several researchers have proposed a modification to this by setting the velocity to non-zero minimum speed. With this the network becomes more stable and reliable, hence converges simulation results to a constant and stable level $\frac{36,37}{}$. We adopted this improve model in our simulations.

\subsection{Energy Model for MANET}

In the earlier sections, we stated the primary goal of a routing protocol is efficient when a route is established between the source and the target destination. The availability of link and route to a destination node ${ }^{38}$ determines the survivability of the network. To establish a route to the destination without affecting the performance, energy should be conserved for critical nodes ${ }^{40}$. Ultimate goal is to conserve energy of the nodes $s^{38,39}$. In our model, energy awareness is implemented as a part of routing protocol at the network layer. When the number of active connections is more, we use reactive routing protocol like AODV. On the contrary DSR saves bandwidth and reduces power consumption as it doesn't use periodic routing relay. During link failures also, source nodes have the capability of checking its own cache for an alternate route. At any point of time the activities performed by the nodes is either transmit data packets, or receive data from neighbor nodes or idle neither transmits nor receives. The energy consumption is directly proportional to the bandwidth and size of the packet being transmitted.

\section{Simulation Model for MANET}

Our simulation is performed on two different models to evaluate MANET routing protocols. First is mobility model and second is energy model. The important characteristics of mobile nodes are the node positions and speed. The node positions are assumed to change constantly with respect to time. The pause time of a network decides the time taken for the nodes to change their positions or start sending packets to destination. Hence, in our work to observe the performance of a network variable pause times are considered. Also speed of nodes is another variable considered for evaluation of network performance. Similarly, in energy model the power of mobile nodes along with their mobility are considered as the essential properties of mobile nodes. Like mobil- ity model, to evaluate the performance of network, we considered variable pause time and speed of nodes. In the energy model we considered some extra parameters as compared to mobility model such as initial energy, idle, or receiving or transmission or sleep power etc. The working procedure proposed work has been outlined in Figure 3.

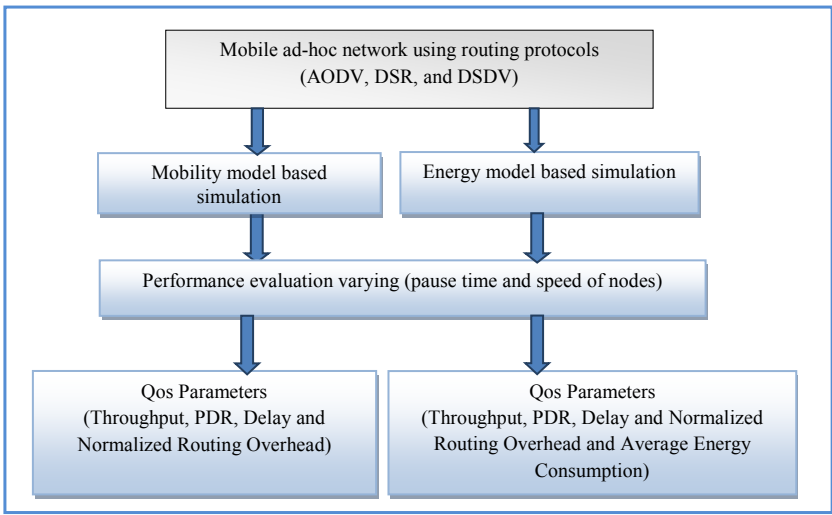

Figure 3. Working procedure of simulation model for MANET.

\subsection{Performance Parameters}

Performance parameters are used to measure the efficiency of a routing protocol in different situations. In MANET, the mobile nodes are not constantly present at a single position, so it is a very challenging task to maintain the network stability along with its performance. Two different models are taken to simulate a MANET. One is mobility model and the other is energy model. In mobility model the node positions and speed are considered as the important characteristics of mobile nodes. Similarly, in energy model the power of mobile nodes along with their mobility are considered as the main properties of mobile nodes. As we know, mobile nodes move constantly and their performance depends on the power consumed by the mobile nodes hence a simulation has been performed with energy model for different routing protocols. To evaluate the performance of MANET for two different models we have considered four parameters as discussed in section 1 such as; TP, PDR, AD and NOR. Along with these four parameters one extra parameter has been taken for energy model that is average energy consumption (AEC).The parameters are explained mathematically as follows from equation (1) to (4).

$$
\begin{gathered}
T P=\frac{\text { Total number of delivered packets }}{\text { Total simulation time }} \\
P D R=\frac{\text { Total number of packets recieved by reciever }}{\text { Total number of packets sent by sent }} \times 100
\end{gathered}
$$




$$
\begin{aligned}
& A D=\frac{\sum_{i=0}^{\text {seq. no. }} \text { delay }[\mathrm{i}]}{\text { count }} \\
& N R O=\frac{\text { Total number of routing packets }}{\text { Total number of deliver packets }}
\end{aligned}
$$

\subsection{Simulation Results and Discussion}

This section demonstrates about the results obtained from ns2 simulation of MANET using routing protocols AODV, DSDV and DSR. Table 6 shows the simulation environment setup for MANET using a mobility based model for different pause times. Here, the pause times are considered as $0,30,60,90,120,150$ seconds etc. All simulations are performed using NS2.35. The graphical representation of networks is visualized using NAM editor available in NS2. Similarly, the Table 9 shows the simulation environment setup for MANET using mobility based model for different speed of nodes. Speeds are considered like 10, 30, 50, 70, $90 \mathrm{~m} / \mathrm{sec}$ etc. Another model for MANET has been simulated for the energy consumption by the node with respect to movement of nodes. Power consumption is considered as one of the important feature of a MANET which increases or decreases the efficiency and stability of the network. Energy consumption has been evaluated by considering different pause time and speed of the nodes as discussed earlier in case of mobility based model.

\subsubsection{Simulation results for mobility based model}

The simulation environment setup for mobility based model with varying pause time is given in Table $\mathbf{6}$, the comparison of pause time with respect to TP and PDR, $\mathrm{AD}$ and NRO has been shown in Table 7 with Figure 4 and Table 8 with Figure 5 respectively. In all the cases the numbers of nodes are fixed to 50 and the pause time of mobile nodes is varying starting from 0 to total simulation time with a difference of 30 seconds. From Figure 4 it can be clearly understood that the reactive routing protocol DSR dominates its peers that is AODV and DSDV in terms of throughput and. It can be observed that for DSDV the throughput is very poor at 0 pause time but increases as pause time increases. Similarly in terms of delay and routing overhead DSR performs better as compared to others.

Similarly, simulation environment setup for mobility based model with varying speed is given in Table 9, the comparison of speed with respect to TP and PDR, AD and NRO has been shown in Table 10 with Figure 6 and
Table 11 with Figure 7 respectively. In this case, speed of the nodes was varied from $10 \mathrm{~m} / \mathrm{s}$ to $90 \mathrm{~m} / \mathrm{s}$ where as the number of nodes and pause time is kept as fixed value.

We proved that the protocol DSR outperformed for throughput, packet delivery, delay and routing overhead as compared to AODV and DSDV. Also for DSDV the throughput increases significantly as the speed of nodes increase. It can also be observed that for AODV protocol the routing overhead is high as compared to DSR and DSDV with respect to varying speed of nodes in mobility model.

\subsubsection{Scenario 1: Variation in Pause Time for Mobility Based Model}

\subsection{Simulation Profile}

Table 6. Simulation environment setup for mobility based model with varying pause time on three protocols AODV, DSDV and DSR in MANET

\begin{tabular}{|l|l|}
\hline Environment Parameters & Value \\
\hline No. of nodes & 50 \\
\hline Size of rectangle & $600 \times 600$ \\
\hline Simulation time & 150 seconds \\
\hline Agent type & TCP \\
\hline Application type & FTP \\
\hline Packet size & 512 bytes \\
\hline Packet transfer rate & 4 packets/second \\
\hline Mobility model & Random-way point \\
\hline No. of TCP sources & 16 (one third of no. of nodes) \\
\hline Maximum speed & 10 m/s \\
\hline Pause time & $0,30,60,90,120,150$ \\
\hline Protocols & AODV, DSR, DSDV \\
\hline
\end{tabular}

\subsection{Simulation Results}

Table 7. TP and PDR vs. Pause Time

\begin{tabular}{|l|l|l|l|l|l|l|}
\hline Pause & \multicolumn{2}{|l|}{ Throughput } & \multicolumn{3}{l|}{ Packet Delivery Ratio } \\
\cline { 2 - 7 } $\begin{array}{l}\text { Time } \\
\text { in } \\
\text { Seco- } \\
\text { nds }\end{array}$ & AODV & DSDV & DSR & AODV & DSDV & DSR \\
\hline 0 & 97.17 & 39.4 & 161.97 & 100.16 & 100.45 & 103.58 \\
\hline 30 & 116.27 & 81.77 & 161.11 & 100.67 & 100.39 & 103.45 \\
\hline 60 & 118.99 & 112.02 & 160.41 & 100.85 & 100.71 & 110.03 \\
\hline 90 & 129.04 & 104.39 & 140.59 & 103.07 & 100.68 & 115.22 \\
\hline 120 & 131.94 & 138.47 & 145.66 & 100.41 & 100.99 & 110.77 \\
\hline 150 & 130.65 & 117.77 & 141.1 & 100.7 & 102.18 & 108.05 \\
\hline
\end{tabular}



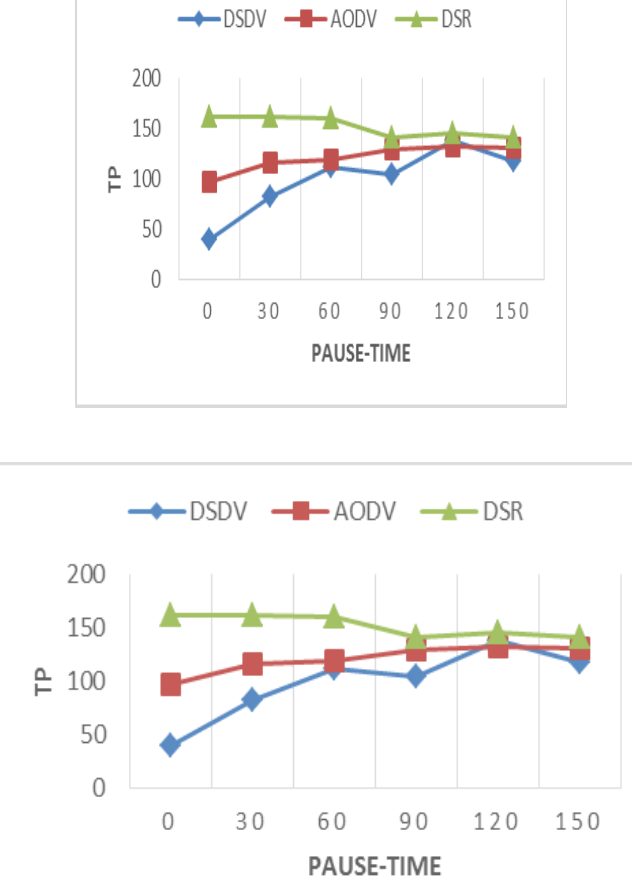

Figure 4. TP varying Pause time and PDR varying Pause time

Table 8. AD and NRO vs. Pause Time

\begin{tabular}{|l|l|l|l|l|l|l|}
\hline $\begin{array}{l}\text { Pause } \\
\text { Time } \\
\text { in } \\
\begin{array}{l}\text { Seco- } \\
\text { nds }\end{array}\end{array}$ & \multicolumn{4}{|l|}{ Average Delay } & \multicolumn{4}{l|}{$\begin{array}{l}\text { Normalized Routing } \\
\text { Overhead }\end{array}$} \\
\cline { 2 - 7 } & AODV & DSDV & DSR & AODV & DSDV & DSR \\
\hline 0 & 239.49 & 249.16 & 240.98 & 0.051 & 0.09 & 0.032 \\
\hline 30 & 255.64 & 153.75 & 237.89 & 0.127 & 0.115 & 0.11 \\
\hline 60 & 296.74 & 173.96 & 239.28 & 0.049 & 0.171 & 0.035 \\
\hline 90 & 162.42 & 198.89 & 238.41 & 0.208 & 0.145 & 0.044 \\
\hline 120 & 230.62 & 242.96 & 236.43 & 0.177 & 0.192 & 0.049 \\
\hline 150 & 353.96 & 152.39 & 239.83 & 0.029 & 0.115 & 0.03 \\
\hline
\end{tabular}

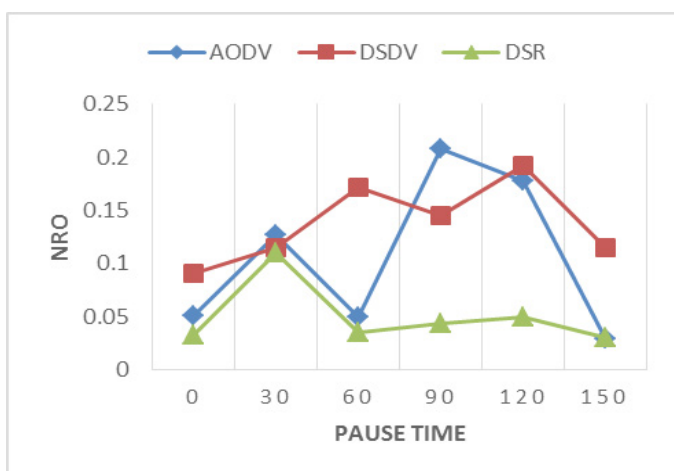

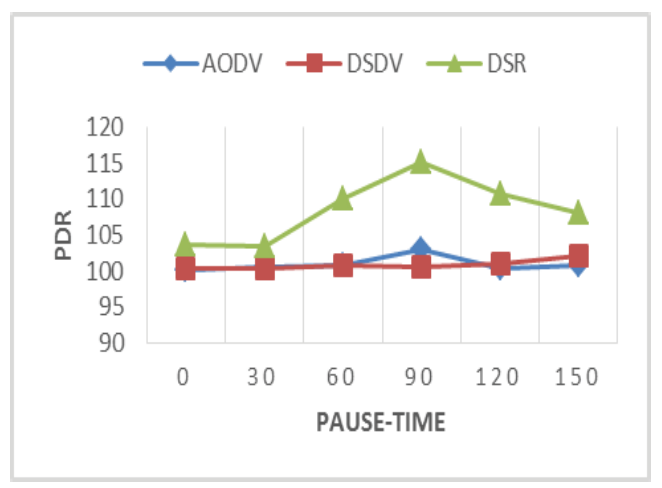

Figure 5. AD varying Pause time and NRO varying Pause time.

\subsubsection{Scenario 2: Variationin Speed of Nodes for Mobility Based Model}

\subsection{Simulation Profile}

Table 9. Simulation environment setup for mobility based model with varying speed of nodes on three protocols AODV, DSDV and DSR in MANET

\begin{tabular}{|l|l|}
\hline Environment Parameters & Value \\
\hline No. of nodes & 50 \\
\hline Size of rectangle & $600 \times 600$ \\
\hline Simulation time & 150 seconds \\
\hline Agent type & TCP \\
\hline Application type & FTP \\
\hline Packet size & 512 bytes \\
\hline Packet transfer rate & 4 packets/second \\
\hline Mobility model & Random-way point \\
\hline No. of TCP sources & 16 (one third of no. of nodes) \\
\hline Maximum speed & $10,30,50,70,90$ m/s \\
\hline Pause time & 0 \\
\hline Protocols & AODV, DSR, DSDV \\
\hline
\end{tabular}

\subsection{Simulation Results}

Table 10. TP and PDR varying Speed

\begin{tabular}{|c|c|c|c|c|c|c|}
\hline \multirow{2}{*}{$\begin{array}{l}\text { Spe- } \\
\text { ed in } \\
\mathrm{m} / \\
\mathrm{sec}\end{array}$} & \multicolumn{3}{|c|}{ Throughput } & \multicolumn{3}{|c|}{ Packet Delivery Ratio } \\
\hline & AODV & DSDV & DSR & AODV & DSDV & DSR \\
\hline 10 & 117.39 & 137.26 & 153.17 & 100.16 & 100.55 & 100.17 \\
\hline 30 & 93.03 & 159.55 & 161.96 & 100.51 & 100.18 & 100.16 \\
\hline 50 & 139.3 & 157.42 & 160.4 & 100.62 & 100.47 & 100.99 \\
\hline 70 & 145.68 & 141.76 & 161.54 & 100.25 & 100.8 & 100.66 \\
\hline 90 & 152.75 & 150.29 & 159.62 & 100.2 & 100.44 & 102.78 \\
\hline
\end{tabular}



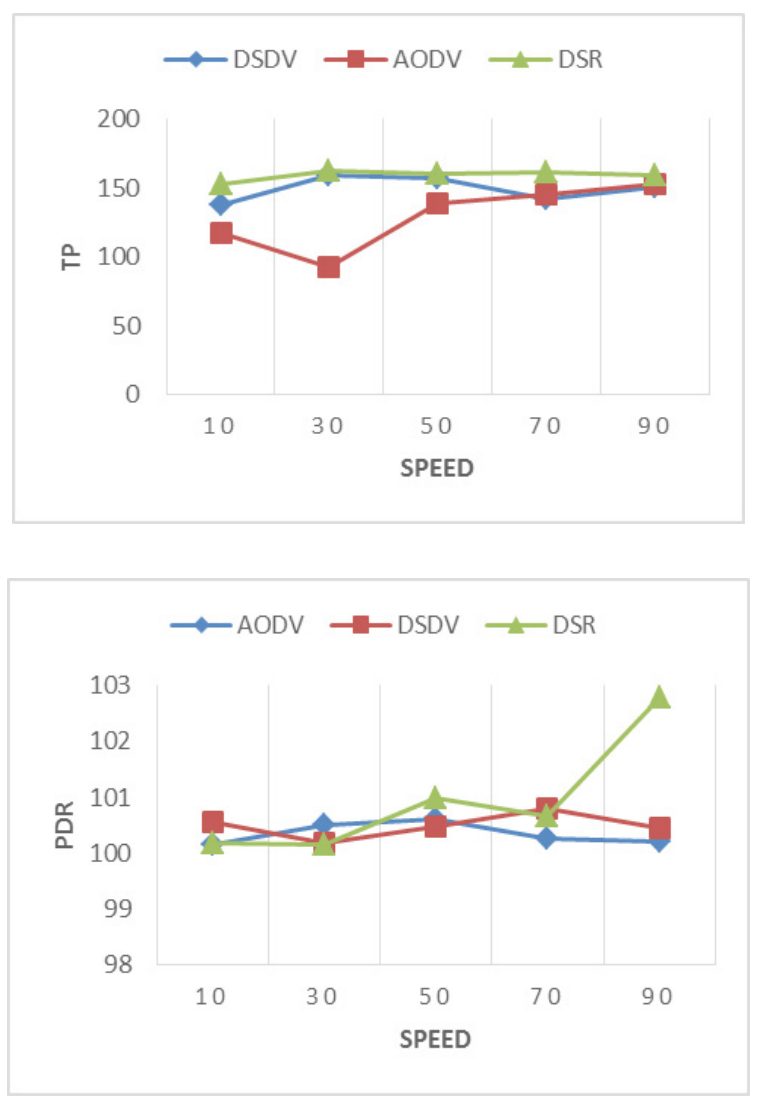

Figure 6. TP varying Speed and PDR varying Speed.

Table 11. AD and NRO vs. Speed

\begin{tabular}{|l|l|l|l|l|l|l|}
\hline \multirow{2}{*}{$\begin{array}{l}\text { Speed } \\
\text { in } \\
\text { sec }\end{array}$} & \multicolumn{3}{|l|}{ Average Delay } & \multicolumn{3}{l|}{$\begin{array}{l}\text { Normalized Routing } \\
\text { Overhead }\end{array}$} \\
\cline { 2 - 7 } & AODV & DSDV & DSR & AODV & DSDV & DSR \\
\hline 10 & 239.26 & 250.22 & 257.48 & 0.071 & 0.099 & 0.002 \\
\hline 30 & 258.04 & 236.5 & 245.65 & 0.035 & 0.071 & 0.002 \\
\hline 50 & 234.96 & 215.63 & 217.91 & 0.047 & 0.078 & 0.043 \\
\hline 70 & 215.46 & 197.18 & 242 & 0.188 & 0.097 & 0.007 \\
\hline 90 & 224.51 & 209.86 & 225.32 & 0.21 & 0.093 & 0.021 \\
\hline
\end{tabular}

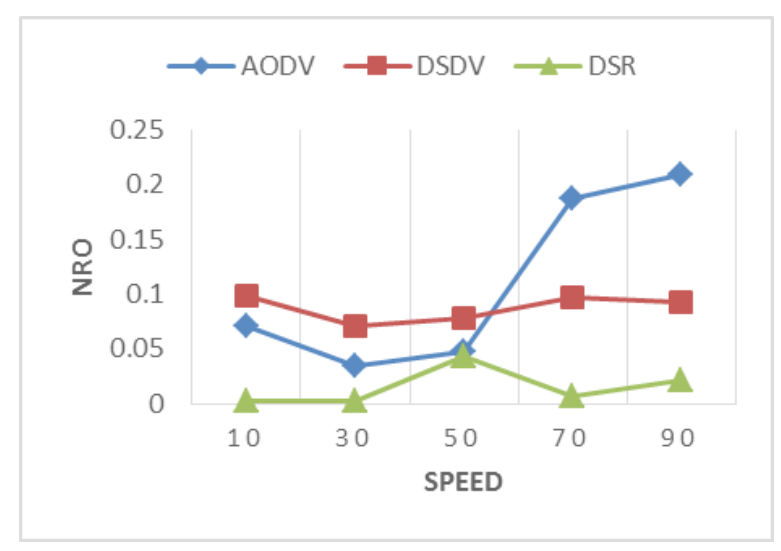

Vol 9 (37) | October 2016 | www.indjst.org

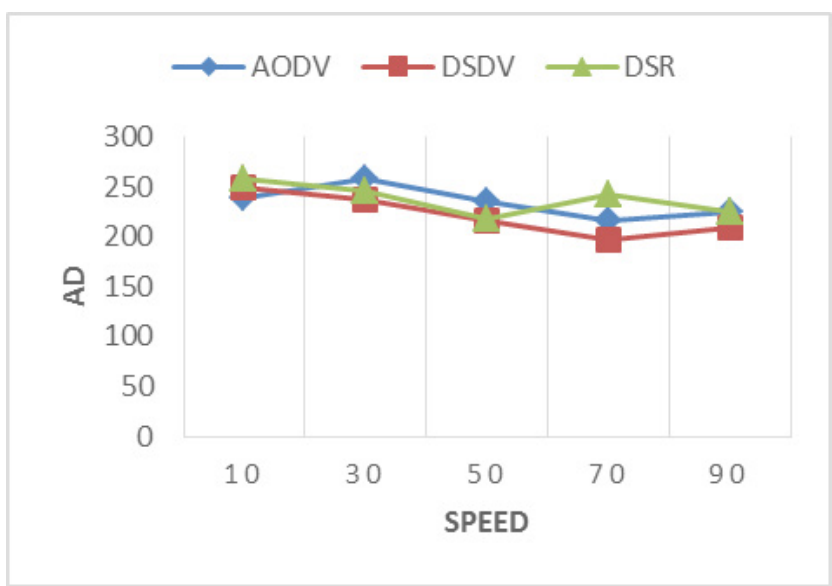

Figure 7. AD varying Speed and NRO varying Speed.

\subsubsection{Simulation results for energy based model}

The simulation environment setup for energy based model with varying pause time is given in Table 12, the comparison of pause time with respect to TP and PDR, $\mathrm{AD}$ and NRO and AEC has been shown in Table 13 with Figure 8, Table 14 with Figure 9 and Table 15 with Figure 10respectively. There is a similar type of comparisons made for evaluation of routing protocols based on energy model like we have already done for mobility based model. The node while moving in the simulated space and transmitting the packets, the average energy consumption by the nodes is calculated. From the graphs we observe that in the energy model, DSDV protocol out performs than others. There is no significant improvement in TP and PD as compared toDSR. DSR protocol still would be considered for better TP\& PD. Most importantly it can be clearly seen from the graphs the average energy consumed by DSR protocol significantly low as compared to DSDV and AODV. This means we can achieve high performance from a MANET with DSR routing protocol with less energy consumed by the mobile nodes. All these observations have been made by varying the pause time.

Similarly, simulation environment setup for mobility based model with varying speed is given in Table 16, the comparison of speed with respect to TP and PDR, AD and NRO and AEC has been shown in Table 17 with Figure 11, Table 18 with Figure 12 and Table 19 with Figure 13respectively. Similarly a different set of observations have been made to evaluate performance of network with varying speed. We can observe the same behavior as previous. But the most important alteration we can see there is an increase in routing overhead for DSR protocol as the speed of nodes increases. However the energy consumption is still low as compared to others. 


\subsubsection{Scenario 3: Variation in Pause Time for Energy} Based Model

\subsection{Simulation Profile}

Table 12. Simulation environment setup for energy based model with varying pause time using three protocols AODV, DSDV and DSR in MANET

\begin{tabular}{|l|l|}
\hline Environment Parameters & Value \\
\hline No. of nodes & 10 \\
\hline Size of rectangle & $600 \times 600$ \\
\hline Simulation time & $0-150$ seconds \\
\hline Agent type & TCP \\
\hline Application type & FTP \\
\hline Packet size & 512 bytes \\
\hline Packet transfer rate & 4 packets/second \\
\hline Mobility model & Random-way point \\
\hline No. of TCP sources & 3 (one third of no. of nodes) \\
\hline Maximum speed & $10 \mathrm{~m} / \mathrm{s}$ \\
\hline Pause time & $0,30,60,90,120,150$ \\
\hline Protocols & AODV, DSR, DSDV \\
\hline Initial Energy & 1000 Joules \\
\hline Idle power & $1.0 \mathrm{w}$ \\
\hline Transmission Power & $1.0 \mathrm{w}$ \\
\hline Receiving Power & $1.0 \mathrm{w}$ \\
\hline Sleep Power & $0.001 \mathrm{w}$ \\
\hline Transition Power & $0.2 \mathrm{w}$ \\
\hline Transition Time & $0.005 \mathrm{sec}$ \\
\hline
\end{tabular}

\subsection{Simulation Results}

Table 13. TP and PDR vs. Pause Time

\begin{tabular}{|l|l|l|l|l|l|l|}
\hline $\begin{array}{l}\text { Pause } \\
\text { Time } \\
\text { in } \\
\begin{array}{l}\text { Seco- } \\
\text { nds }\end{array}\end{array}$ & \multicolumn{3}{|l|}{ Throughput } & \multicolumn{3}{l}{ Packet Delivery Ratio } \\
\hline & AODV & DSDV & DSR & AODV & DSDV & DSR \\
\hline 0 & 125.96 & 151.87 & 158.52 & 100.53 & 102.08 & 100.53 \\
\hline 30 & 133.27 & 135.42 & 153.88 & 101.76 & 102.16 & 101.01 \\
\hline 60 & 108.08 & 140.87 & 150.76 & 102.49 & 101.93 & 100.93 \\
\hline 90 & 122.78 & 138.43 & 152.3 & 101.41 & 106.81 & 100.67 \\
\hline 120 & 129.24 & 133.87 & 157.58 & 101.45 & 105.35 & 100.5 \\
\hline 150 & 125.93 & 150.88 & 150.75 & 100.8 & 106.66 & 100.52 \\
\hline
\end{tabular}

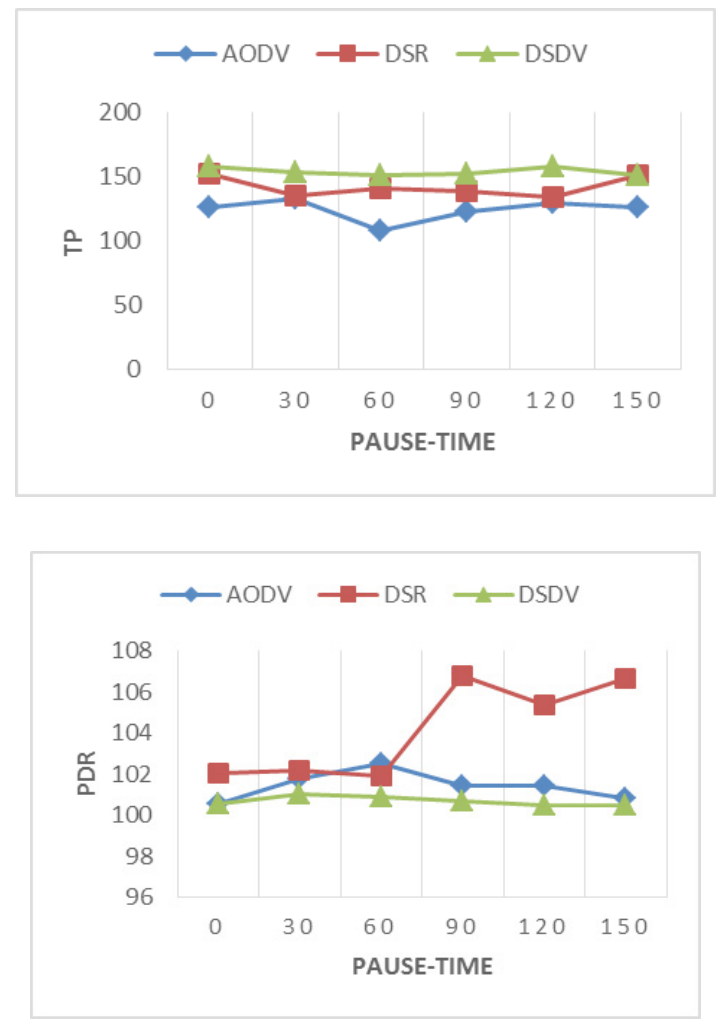

Figure 8. TP varying Pause time and PDR varying Pause time.

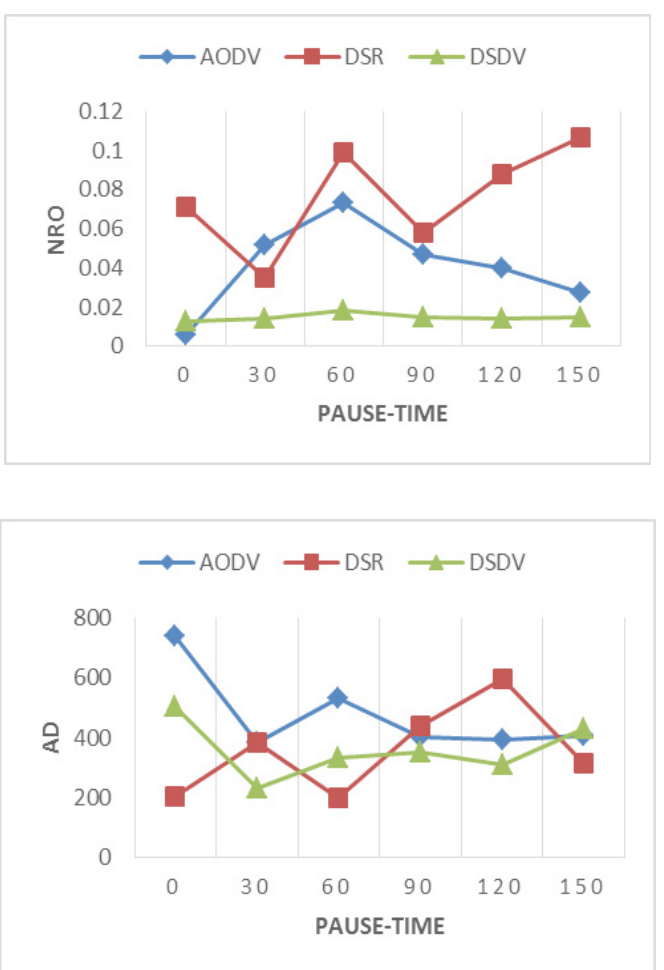

Figure 9. AD varying Pause time and NRO varying Pause time. 
Table 14. AD and NRO vs. Pause Time

\begin{tabular}{|l|l|l|l|l|l|l|}
\hline $\begin{array}{l}\text { Pause } \\
\text { Time } \\
\text { in Sec- } \\
\text { onds }\end{array}$ & \multicolumn{4}{|c|}{ Average Delay } & \multicolumn{3}{c|}{$\begin{array}{c}\text { Normalized Routing } \\
\text { Overhead }\end{array}$} \\
\hline & AODV & DSDV & DSR & AODV & DSDV & DSR \\
\hline 0 & 738.71 & 205.41 & 503.77 & 0.006 & 0.071 & 0.013 \\
\hline 30 & 385.73 & 384.71 & 228.84 & 0.052 & 0.035 & 0.014 \\
\hline 60 & 530.5 & 196.57 & 332.89 & 0.073 & 0.099 & 0.018 \\
\hline 90 & 402.11 & 441.51 & 352.91 & 0.047 & 0.058 & 0.015 \\
\hline 120 & 391.64 & 598.07 & 309.45 & 0.04 & 0.088 & 0.014 \\
\hline 150 & 408.59 & 315.65 & 431.8 & 0.027 & 0.107 & 0.015 \\
\hline
\end{tabular}

Table 15. AEC vs. Pause Time

\begin{tabular}{|l|l|l|l|}
\hline Pause Time & Average Energy & & \\
\hline & AODV & DSR & DSDV \\
\hline 0 & 299.963 & 234.113 & 299.998 \\
\hline 30 & 299.679 & 248.689 & 298.732 \\
\hline 60 & 299.62 & 134.117 & 299.725 \\
\hline 90 & 299.331 & 216.875 & 299.617 \\
\hline 120 & 297.597 & 127.59 & 297.556 \\
\hline 150 & 289.232 & 113.785 & 299.66 \\
\hline
\end{tabular}

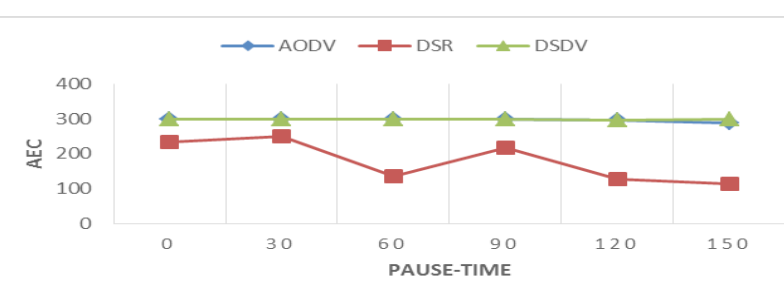

Figure 10. AEC varying Pause time.

\subsubsection{Scenario 4: Variation in Speed of Nodes for Energy Based Model}

\subsection{Simulation Profile}

Table 16. Simulation environment setup for energy based model with varying speed on three protocols AODV, DSDV and DSR in MANET

\begin{tabular}{|l|l|}
\hline Environment Parameters & Value \\
\hline No. of nodes & 10 \\
\hline Size of rectangle & $600 \times 600$ \\
\hline Simulation time & 150 seconds \\
\hline Agent type & TCP \\
\hline
\end{tabular}

\begin{tabular}{|l|l|}
\hline Application type & FTP \\
\hline Packet size & 512 bytes \\
\hline Packet transfer rate & 4 packets/second \\
\hline Mobility model & Random-way point \\
\hline No. of TCP sources & 3 (one third of no. of nodes) \\
\hline Maximum speed & $10,30,50,70,90 \mathrm{~m} / \mathrm{s}$ \\
\hline Pause time & 0 \\
\hline Protocols & AODV, DSR, DSDV \\
\hline Initial Energy & $1000 \mathrm{Joules}$ \\
\hline Idle power & $1.0 \mathrm{w}$ \\
\hline Transmission Power & $1.0 \mathrm{w}$ \\
\hline Receiving Power & $1.0 \mathrm{w}$ \\
\hline Sleep Power & $0.001 \mathrm{w}$ \\
\hline Transition Power & $0.2 \mathrm{w}$ \\
\hline Transition Time & $0.005 \mathrm{sec}$ \\
\hline
\end{tabular}

\subsection{Simulation Results}
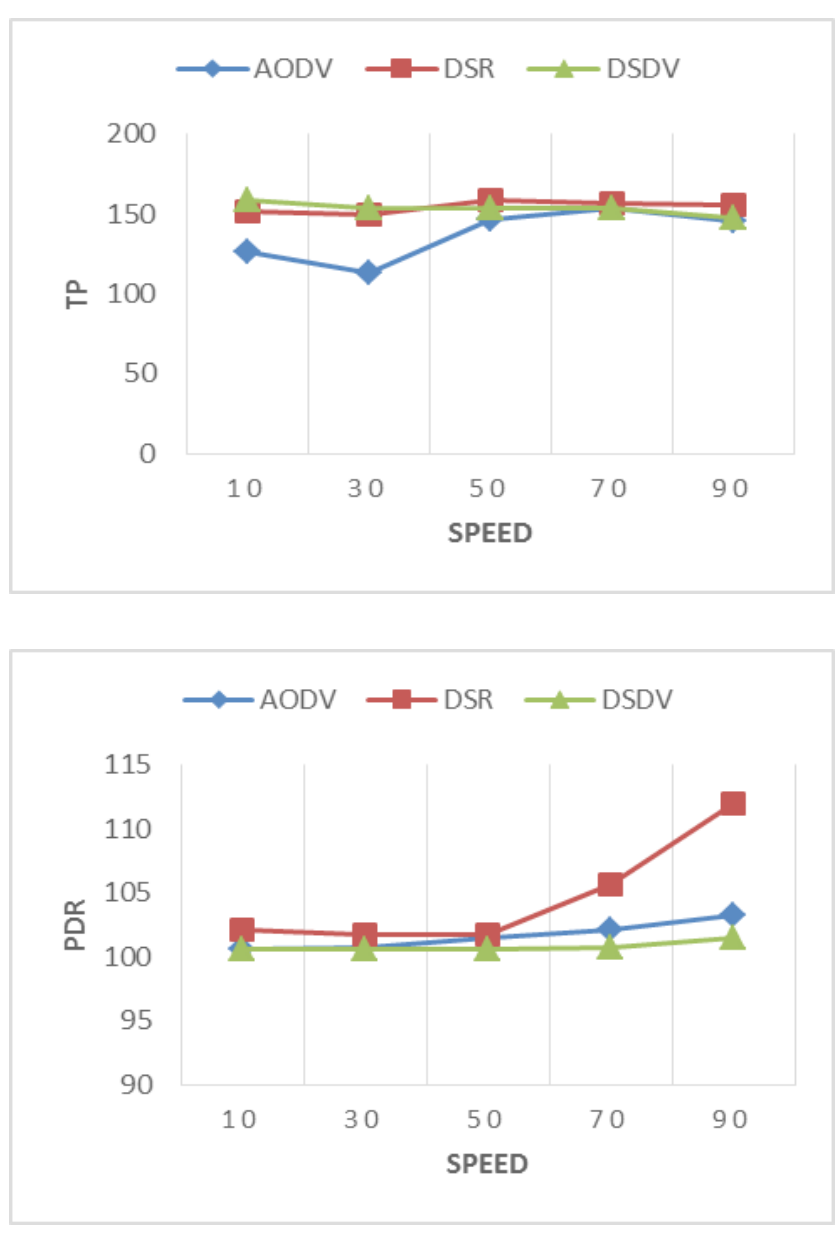

Figure 11. TP varying Speed and PDR varying Speed. 
Table 17. TP and PDR vs. Speed

\begin{tabular}{|l|l|l|l|l|l|l|}
\hline \multirow{2}{*}{$\begin{array}{l}\text { Speed } \\
\text { in m/ } \\
\text { sec }\end{array}$} & \multicolumn{3}{|l|}{ Throughtput } & \multicolumn{3}{l|}{ Packet Delivery Ratio } \\
\cline { 2 - 7 } & AODV & DSDV & DSR & AODV & DSDV & DSR \\
\hline 10 & 125.96 & 151.87 & 158.52 & 100.53 & 102.08 & 100.53 \\
\hline 30 & 113 & 149.34 & 153.44 & 100.7 & 101.74 & 100.64 \\
\hline 50 & 145.98 & 158.76 & 153.96 & 101.42 & 101.78 & 100.63 \\
\hline 70 & 153.64 & 156.54 & 153.6 & 102.15 & 105.66 & 100.75 \\
\hline 90 & 145.12 & 155.39 & 147.01 & 103.19 & 111.96 & 101.43 \\
\hline
\end{tabular}

Table 18. AD and NRO vs. Speed

\begin{tabular}{|l|l|l|l|l|l|l|}
\hline \multirow{2}{*}{$\begin{array}{l}\text { Speed } \\
\text { in } \mathbf{m} \text { / } \\
\text { sec }\end{array}$} & \multicolumn{4}{|l|}{ Average Delay } & \multicolumn{4}{l|}{$\begin{array}{l}\text { Normalized Routing } \\
\text { Overhead }\end{array}$} \\
\cline { 2 - 7 } & AODV & DSDV & DSR & AODV & DSDV & DSR \\
\hline 10 & 738.71 & 205.41 & 503.77 & 0.006 & 0.071 & 0.013 \\
\hline 30 & 730.12 & 492.07 & 559.05 & 0.006 & 0.023 & 0.013 \\
\hline 50 & 547 & 385.32 & 472.94 & 0.024 & 0.026 & 0.013 \\
\hline 70 & 471.45 & 375.37 & 480.21 & 0.035 & 0.062 & 0.014 \\
\hline 90 & 388.64 & 212.61 & 417.06 & 0.068 & 0.213 & 0.013 \\
\hline
\end{tabular}
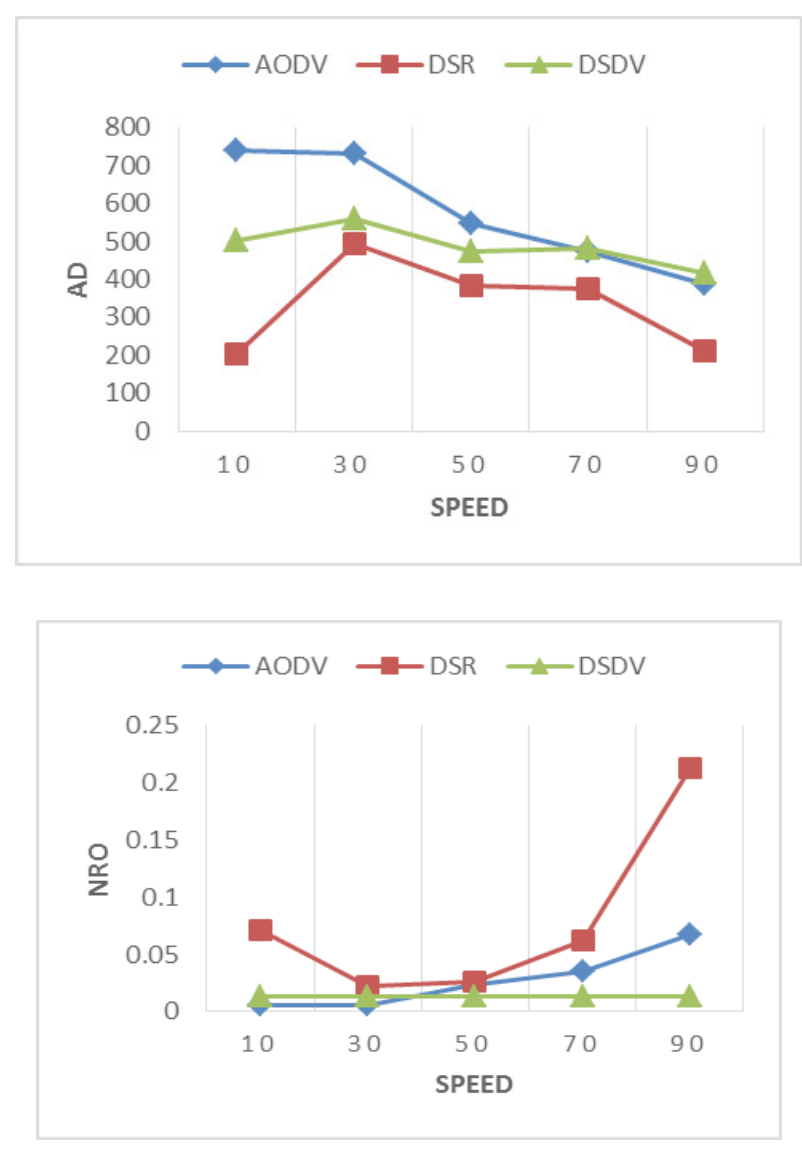

Figure 12. AD varying Speed and NRO varying Speed.

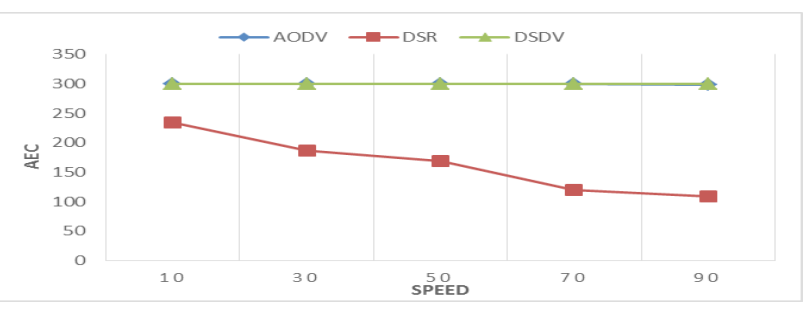

Figure 13. AEC vs. Speed

Table 19. AEC vs. Speed

\begin{tabular}{|l|l|l|l|}
\hline \multirow{2}{*}{$\begin{array}{l}\text { Speed in } \\
\text { m/sec }\end{array}$} & \multicolumn{4}{|l|}{ Average Energy } \\
\cline { 2 - 4 } & AODV & DSR & DSDV \\
\hline 10 & 299.963 & 234.113 & 299.998 \\
\hline 30 & 299.922 & 186.968 & 299.873 \\
\hline 50 & 299.996 & 168.527 & 299.897 \\
\hline 70 & 299.948 & 120.302 & 299.64 \\
\hline 90 & 297.994 & 109.028 & 299.942 \\
\hline
\end{tabular}

\section{Conclusion}

The experimental evaluation of the MANET routing protocols AODV, DSDV and DSR on mobility based and energy based models considering the QoS parameters throughput, packet delivery ratio, and average delay and normalized routing overhead resulted in drawing the aforesaid conclusion.

We can conclude that the DSR protocol dominates all other protocols like AODV and DSDV. The Dynamic Source Routing protocol in mobility and energy based model for throughput, packet delivery ratio performs well than AODV and DSDV. The adverse result is that, with the increase of node speed, routing overhead increased for DSR. Positive aspect of DSR was that average energy consumption was quite low in contrast to AODV and DSDV.

\section{References}

1. Vijayakumar K, Somasundaram K. Study on reliable and secure routing protocols on manet. Indian Journal of Science and Technology. 2016 Apr; 9(14):1-10.

2. Anand V Sairam N. Methodologies for Addressing the performance issues of routing in mobile ad hoc networks. Indian Journal of Science and Technology. 2015 Jul; 8(15):1-10.

3. Abdulsaheb G, Khalaf O, Sulaiman N, Zmezm H, Zmezm $\mathrm{H}$. Improving ad hoc network performance by using an 
efficient cluster based routing algorithm. Indian Journal of Science and Technology. 2015 Nov; 8(30):1-8.

4. Rupinder K, Paramdeep S, Singh GG, Ruchi P. Performance enhancement of AODV with distributed - DSR routing protocol in MANET. Indian Journal of Science and Technology. 2015 Oct; 8(28):1-6.

5. Pearlin RFSP, Rekha G. Performance Comparison of AODV, DSDV and DSR Protocols in Mobile Networks using NS-2. Indian Journal of Science and Technology. 2016; 9(8):1-7.

6. Ahmadi M, Shojafar M, Khademzadeh A. Hybrid Algorithm for Preserving Energy and Delay Routing in Mobile Ad-Hoc Networks. Wireless Personal Communications. 2015; 85(4):2485-505.

7. Song J, Chin K. A survey of single and multi-hop link schedulers for $\mathrm{mm}$ Wave wireless systems. Ad Hoc Networks. 2015; 33:269-283.

8. Mallikarjun B, Channappagoudar C, Venkataram P. Performance evaluation of mobile agent based resource management protocol for MANETs. Ad Hoc Networks. 2016; 36 (1):308-20.

9. Yuan B, Ruimin H, Jie A, Huibing Z. Location-aided and secure routing protocol for heterogeneous multi-hop wireless networks. The Journal of China Universities of Posts and Telecommunications. 2016; 23(1):49-54.

10. Aggarwal B, Gupta M, Gupta AK. A comparative study of various current mirror configurations: Topologies and characteristics. Microelectronics Journal. 2016; 53:134-55.

11. Siakoulis Y, Galiotos P, Dagiuklas T, Kotsopoulo S. The impact of simulation duration on the performance of the OLSR, AODV and DSDV Protocols, in a heavyloaded Ad-hoc wireless mobile environment. First IEEE International Conference on System Informatics and Modeling, Greece. 2014. p. 160-7.

12. Mehmood Z, Iqbal M, Wang X. Comprehensive experimental performance analysis of DSR, AODV and DSDV routing protocol for different metrics values with predefined constraints. International Journal of Information Technology and Computer Science. 2014; 6(7):24-31.

13. Kaur D, Kumar N. Comparative analysis of AODV, OLSR, TORA, DSR and DSDV. International Journal Computer Network and Information Security. 2013; 5(3):39-46.

14. Mittal P, Singh P, Rani S. Performance analysis of AODV, OLSR, GRP and DSR routing protocols with database load in MANET. International Journal of Research in Engineering and Technology. 2013; 2(9):412-20.

15. Sharma LD, Roberts N. Effects of velocity on performance of DYMO, AODV and DSR routing protocols in mobile Ad-hoc networks. Procedia Technology. 2012; 4:727-31.

16. Ashtiani H, Moradi H, Pour P, Nikpour M. A Survey of MANET Routing Protocols in Large-Scale and Ordinary Networks. Global Journal of Computer Science and Technology. 2010; 10(13):39-46.
17. Jayakumar G, Gopinath G. Ad Hoc Mobile Wireless Networks Routing Protocols - A Review. Journal of Computer Sciences. 2007; 3(8):574-82.

18. ShenZhuochuan CC, Jaikaeo HC. Directional broadcast for mobile ad hoc networks with percolation theory. IEEE Transactions on Mobile Computing. 2006; 5(4):317-32.

19. Kant L, Demers S, Gopalakrishnan P, Chadha R, Vergne LL, Newman S. Performance modeling and analysis of a mobile ad hoc network management system. The research reported with contract number DAAD19-01-C-0062 with the U.S. Army Research Laboratory, USA. 2005; 1-7.

20. Se-Young L. An ANT system based multicasting in mobile adhoc network. IEEE, South korea. 2005.

21. Detti AA, Loreti C, Loreti P. Effectiveness of overlay multicasting in mobile ad-hoc network. IEEE International Conference on Communications, Italy. 2004. p. 20-4.

22. Rangnekar A, Zhang Y, Ali A, Selcuk S, Bicak A, Devarapalli V, Sidhu D. A Zone-Based Shared-Tree Multicast Protocol for Mobile Ad Hoc Networks. Vehicular Technology Conference, Baltimore. 2003.

23. Yuan P, Fan L, Liu p, Tang S. Recent progress in routing protocols of mobile opportunistic networks: A clear taxonomy, analysis and evaluation. Journal of Network and Computer Applications. 2016; 62:163-70.

24. Tripathi J, Jaudelice C, Oliveira D, Vasseur JP. Proactive versus reactive routing in low power and Lossy networks: Performance analysis and scalability improvements. Ad Hoc Networks. 2014; 23:121-44.

25. Shadi S, Basurraa B, Vosa MD, Padgeta J, Jib Y, Lewisc T, Armourd S. Energy efficient zone based routing protocol for MANETs. Ad Hoc Networks. 2015; 25(A):16-37.

26. Annapurna S, Mishra M, Shailendra S. Performance Analysis of reactive routing protocols in Mobile ad-hoc Networks. International Journal of Computer Science and Network Security. 2010. 10(8):141-5.

27. Shivahare BD, Wahi C, Shivhare S. Comparison of Proactive and Reactive Routing Protocols in Mobile Adhoc Network using Routing Protocol Property. International Journal of Emerging Technology and Advanced Engineering. 2012; 2(3):356-9.

28. Patil VP. Reactive and Proactive Routing Protocol Performance Evaluation for Qualitative and Quantitative Analysis in Mobile Ad Hoc Network. International Journal of Scientific and Research Publications. 2012; 2(9):1-8.

29. Annapurna S, Mishra M, Shailendra S. Performance Analysis of reactive routing protocols in Mobile ad-hoc Networks. International Journal of Computer Science and Network Security. 2010; 10(8):141-5.

30. Shanmugam K, Subburathinam K, Palanisamy AV. A Dynamic Probabilistic Based Broadcasting Scheme for MANETs. The Scientific World Journal, (Article ID 1832026). 2016. p. 1-8. 
31. Shadi S, Basurraa B, Vosa MD, Padgeta J, Jib Y, Lewisc T, Armourd S. Energy efficient zone based routing protocol for MANETs. Ad Hoc Networks. 2015; 25(A):16-37.

32. Kaur S. Performance evaluation of hybrid routing protocols in mobile ad hoc network. International Journal of Advanced Research in Computer Science and Software Engineering. 2013; 3(9):634-40.

33. Almomani O, Al-shugran M, Jafar A, Omar AA, Alzubi A. Performance Evaluation of Position-based Routing Protocols using Different Mobility Models in MANET. International Journal of Computer Applications. 2015; 119(3):43-8.

34. Izuan M, Saad M. Performance Analysis of Random-Based Mobility Models in MANET Routing Protocol. European Journal of Scientific Research. 2009; 32(4):444-54.

35. Bettstetter C, Hartenstein H, Perez-Costa X. Stochastic Properties of the Random Waypoint Mobility Model. Wireless Networks. 2004; 10(5):555-67.

36. Camp T, Boleng J, Davies V. A survey of mobility models for ad hoc network research. Wireless Communications \&
Mobile Computing (WCMC): Special issue on Mobile Ad Hoc Networking: Research, Trends and Applications. 2002; 2(5):483-502.

37. Ejiro E, Igbesoko I, Eze TO, Ghassemian M. Performance analysis of MANET routing protocols over different mobility models. In Proceedings of London Communications Symposium (LCS), University College London. 2010; 1-4.

38. Sumathi N, Thanamani AS. Evaluation of Energy Efficient Reactive Routing Protocols in QoS Enabled Routing for MANETS. International Journal of Computer Applications. 2011; 14(2):10-4.

39. Lim S, Yu C, Das C. Rcast: A Randomized Communication Scheme for Improving Energy Efficiency in Mobile Ad Hoc Networks. Proc 25th IEEE Int'l Conf Distributed Computing Systems (ICDCS '05). 2005. p. 123-32.

40. Gupta D, Gujral RK. Simulation of Different Routing Protocols in MANET Using NS2. International Journal of Scientific and Research Publications. 2014; 4(8):1-5. 